\title{
Charcot Neuroarthropathy: Current Surgical Management and Update. A Systematic Review
}

\author{
Mohd Yazid Bajuri ${ }^{1 *}$, Shir Lee Ong ${ }^{1}$, Srijit Das ${ }^{2}$ and Isa Naina Mohamed ${ }^{3}$ \\ ${ }^{1}$ Department of Orthopaedic and Traumatology, Faculty of Medicine, Universiti Kebangsaan Malaysia Medical Centre, \\ Kuala Lumpur, Malaysia, ${ }^{2}$ Department of Human Clinical Anatomy, Faculty of Medicine, Universiti Kebangsaan Malaysia \\ Medical Centre, Kuala Lumpur, Malaysia, ${ }^{3}$ Department of Pharmacology, Faculty of Medicine, Universiti Kebangsaan \\ Malaysia Medical Centre, Kuala Lumpur, Malaysia
}

\section{OPEN ACCESS}

Edited by:

Daniel Jupiter,

Scott \& White Memorial Hospital,

United States

Reviewed by:

Konstantinos Markatos,

Salamina Medical Center, Greece

Khaled M. Emara

Ain Shams University, Egypt

${ }^{*}$ Correspondence:

Mohd Yazid Bajur

ezeds007@yahoo.com.my

Specialty section:

This article was submitted to

Orthopedic Surgery,

a section of the journal

Frontiers in Surgery

Received: 23 November 2021

Accepted: 28 January 2022

Published: 08 March 2022

Citation:

Bajuri MY, Ong SL, Das S and

Mohamed IN (2022) Charcot

Neuroarthropathy: Current Surgical

Management and Update. A

Systematic Review.

Front. Surg. 9:820826.

doi: 10.3389/fsurg.2022.820826
Background: Charcot neuroarthropathy of the ankle and the hindfoot is a complex clinical entity with a high risk of amputation. Charcot neuroarthropathy limb reconstruction has been proposed as a limb-salvaging procedure. However, there was a lack of information on the various available reconstruction methods, including the outcomes and complications. The present study aimed to evaluate the current literature and update on the trends regarding the surgical management of Charcot neuroarthropathy of the ankle and the hindfoot.

Methods: All data published from January 2010 to January 2020 that investigated the methods of fixation and their respective outcomes for the surgical reconstruction in Charcot neuroarthropathy were analyzed. The union rate, amputation rates, and complications associated with these techniques were taken for statistical analysis.

Results: A total of 16 studies fit the inclusion criteria of this study, with four Level-III studies and 12 Level-IV studies were included. Ten studies utilized internal fixation only; five used a combination of internal fixation and circular external fixator, whereby there are three comparative studies between internal and external fixations, and two studies applied combined technique of internal and external fixations (hybrid fixation). One study describes the usage of circular external fixation only.

Conclusions: The use of retrograde intramedullary nail as a treatment of choice in the reconstruction of Charcot neuroarthropathy ankle is recommended before an ulcer occurrence. Hydroxyapatite (HA)- coated screws are recommended for the locking mechanism to prevent migration in Charcot neuroarthropathy due to poor bony quality. Hybrid fixation is recommended for reconstruction in a condition of ulceration and more complex deformity as it provides a higher rate of limb salvage with less soft tissue irritation.

Keywords: Charcot, neuroarthropathy, hindfoot, surgical reconstruction, fixation

\section{INTRODUCTION}

Ankle joint complex is a modified synovial hinge joint, which consists of talocalcaneal, tibiotalar, and trans-tarsal joint. Congruency of the bone and ligament within the ankle gives a high level of compatibility and creates a high degree of stability, while less susceptible to degenerative processes if compared with other joints, hips or knees (1). Ankle joint complex bears a force of approximately 
five times body weight during a stance phase in normal gait, and up to 13 times body weight during activities such as running. Mobility of the ankle plays an important role in posture control as well (2).

Charcot neuroarthropathy at the hindfoot and ankle level is more challenging compared to those involving midfoot as the deformities are often multiplanar (3). Changes of gait in Charcot neuroarthropathy limbs are caused by alteration of the biomechanics and proprioception of the involved ankle (1). Malalignment in the Charcot limb is prone to ulceration due to altered plantar pressure, limited soft tissue coverage, and pressure over bony prominence. It is always associated with limb shortening due to bone collapse that is caused by avascular necrosis or a neuropathic fracture (3).

There are several anatomical classifications for Charcot neuroarthropathy based on a destruction pattern to foots and ankles. There are five different types of anatomical destruction and frequency of complications mentioned by Sanders and Frykberg (4) where type I is in forefoot (15\%), type II is in tarsometatarsal joints (40\%), type III is in naviculocuneiform, talonavicular and calcaneocuboid joints (30\%), type IV is in ankle and/or subtalar joint (10\%), and, lastly, type $\mathrm{V}$ is in the calcaneus (5\%) (4). Brodsky classified the disease according to the fourth most commonly affected area in Charcot neuroarthropathy; the most common site is in midfoot $(60 \%)$, followed by hindfoot (30-35\%), and then ankle (9\%), lastly, calcaneal (2\%) (5). Ankle and the subtalar joint was the $2^{\text {nd }}$ most common site for Charcot neuroarthropathy after the Lisfranc joint, according to Sander, Frykberg, and Brodsky $(4,5)$.

Besides anatomical classification, Charcot neuroarthropathy can be staged according to its physiological progression and radiological appearance at the described stage. It is started with a development stage where the affected limb was markedly warm, erythematous, and swollen, evidenced by periarticular fracture and bony debride radiologically, followed by a reduction of the sign of inflammation and radiographic appearance osseous resorption in the coalescence stage. Lastly, the limb will be reached to the remodel stage, where consolidation of a fracture and a deformed bone occur without a sign of inflammation (6). The main goal of managing Charcot neuroarthropathy is to achieve an osseous stable, painless, plantigrade foot ulcer-free foot $(7,8)$. Management of Charcot neuroarthropathy was evolving from amputation traditionally to a reconstructive limb-salvaging procedure. However, there is no existing standard consensus regarding surgical treatment of ankle Charcot neuroarthropathy due to the heterogeneity of the disease entity and clinical presentation. Surgical approaches depend on several factors, such as the location of the deformity, ulceration, infection, stability of an affected joint, and surgeon experience (8). Therefore, a systematic review was done among pieces of literature published from January 2010 to January 2020 regarding the surgical procedures implemented in the ankle Charcot neuroarthropathy reconstruction to gain a more current, comprehensive, and effective reconstruction mode. The

Abbreviations: CN, Charcot neuroarthropathy; HA, Hydroxyapatite; PRISMA, Preferred reporting items for systematic reviews and meta-analysis. objectives of the present study were to analyse the existing literature and update on the current trends of the surgical management of Charcot neuroarthropathy of the ankle and the hindfoot.

\section{METHODOLOGY}

The preferred reporting items for systematic reviews and metaanalysis (PRISMA) checklist was used for the current systematic review (Figure 1). Data were searched through Medline (Ovid, PubMed), Science Direct, Scopus, and Google scholar by using terms: Charcot neuroarthropathy, neuro-osteoarthropathy, osteoarthropathy, neurogenic arthropathy, ankle, hindfoot, surgical, diabetic reconstruction, and fixation. All Englishpublished original papers from January 2010 till January 2020 that comprise of all human or case-control studies, randomized cross-over studies, randomized controlled trials, randomized cross-pilot studies, pre-post-design studies, surgical management at each stage of Charcot arthropathy of ankle or hindfoot, an article in which a long-term outcome post-intervention on Charcot neuroarthropathy is mentioned were included in this study. Papers not published in English, case reports, animal studies, letters to the editor, and review articles were excluded. The terms Charcot arthropathy, neuroarthropathy, neuropathic arthropathy, and neuropathic osteoarthropathy were used interchangeably for this study.

The search was started in May 2019. All the articles were screened independently by the primary author and the second author in three phases: title, abstract, and full-text screening. The number of articles on which all our reviewers agreed in terms of inclusion and exclusion was divided by the total number of double-screened papers to determine inter-observer agreement. Discrepancies among both the first and second authors were resolved by consensus. For full-text assessment and data extraction, all eligible articles follow mutual consensus. Information on demographic of included patients, the method of reconstruction, infection, union, amputation, and hardware complications were counted in this review. The method of application of the technique was extracted among data. The first author collected and screened all included data. The second author independently validated the completed data extraction sheets against the articles.

\section{RESULTS}

Three hundred nineteen reports were yielded from the initial research. Two hundred fifty-four papers remained after duplicates were lifted. Seventy-eight were excluded during title screening, and one 223 out of 176 abstracts were excluded as those were review articles, single case reports, and nonsurgical treatment on Charcot neuroarthropathy. The remaining 53 full texts were assessed for eligibility, five non-English published journals were excluded, and 32 were further eliminated because they had included patients who had undergone Charcot neuroarthropathy surgery in a location other than hindfoot and ankle and did not have separate results for 
Title of Manuscript, article, or studies

identified through database search

$\mathrm{n}=319$

PubMed $n=121$

Science Direct $n=23$

Scopus $n=65$

Google scholar $n=110$

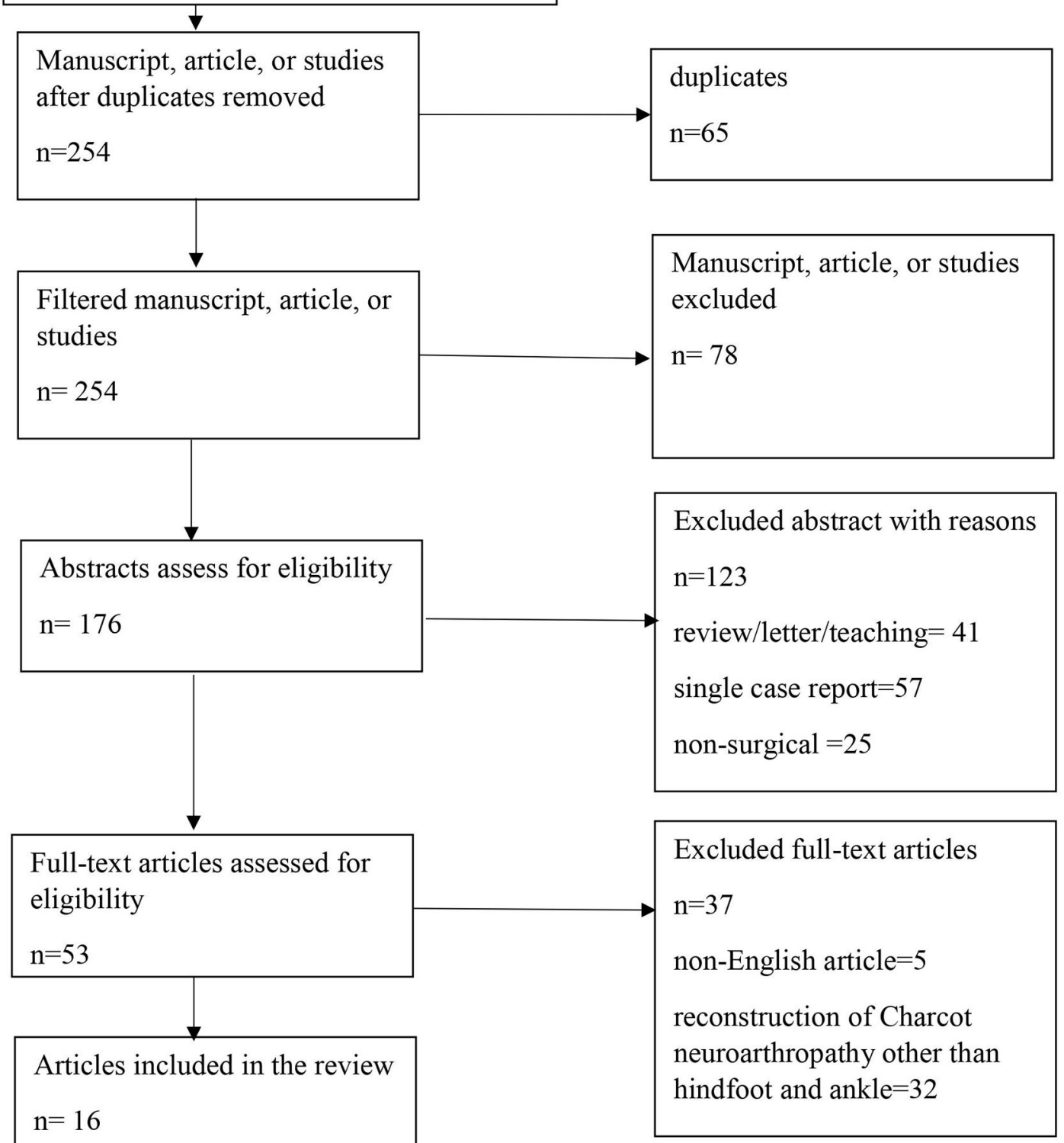

FIGURE 1 | A preferred reporting items for systematic reviews and meta-analyses diagram. 
the Charcot patients receiving surgery. Therefore, 16 studies were included in the outcome analysis regarding the surgical reconstruction of Charcot neuroarthropathy in the hindfoot and the ankle.

Most of the studies were studies with a level of evidence of IV (twelve out of sixteen) (9-20), and remaining studies of four carry the level of evidence of III (21-24). The present study includes three prospective case series $(12,23,24), 12$ retrospective case series $(9-11,13-19,21,22)$; there is only one retrospective cohort (21) with one therapeutic study (20). The most cited procedures were intramedullary nail and circular external fixation or illizarov external fixation. The table below lists the data summarizing this study based on patient demographics (Table 1) and the outcome of these studies (Table 2).

There were five studies conducted in the United States $(11,17$, 18, 20, 22), three in Egypt (12-14), two in the United Kingdom $(18,24)$, and one each from Turkey (9), Italy (21), Austria (10), India (23), and Malaysia (19). All data were collected in the range between 3 to 16 years. Overall, 526 patients were included in these studies with ages ranging from 20-85 years old. The number of patients included per study ranges from four to 73. In Maywood, United States, a center recorded the highest single surgeon series with 73 patients (17). Post-operative follow-up among these studies ranges from 6 to 168 months. Most of the neuropathy associated with Charcot among these studies is diabetes mellitus. Other causes of Charcot were also identified through our search: Hansen disease, myelomalacia, idiopathic peripheral neuropathy, spinal stenosis, and spina bifida $(19,23,24)$.

Overall, 545 procedures were reported to have surgical reconstruction of Charcot neuroarthropathy of the ankle during the study date. The surgical procedures performed included arthrodesis, talectomy, midfoot reconstruction, radical resection of an infected bone, flap, graft, and tendon Achilles lengthening, and medial column fusion. Internal fixation was discussed in 15 studies with 13 utilize retrograde intramedullary nail (10-12, 14$16,18-24)$, one study applied antibiotic coated nail (20), and the others reconstruct via a posterior blade plate (9).

The circular external fixation was chosen as a tool for reconstruction in six studies $(12,13,15-17,22)$. The combination of the retrograde intramedullary nail with a circular external fixator (hybrid fixation) was applied for reconstruction in two studies. There were three comparative studies between internal and circular external fixation $(12,15,22)$ in which two studies reconstruct via the combined technique of internal and circular external fixations (hybrid) $(11,13)$ with one of the studies comparing isolated nail and a combined approach (11). One study describes the usage of circular external fixators only as a mode of reconstruction (17).

\section{DISCUSSION}

Charcot neuroarthropathy $(\mathrm{CN})$ is a progressing disease that weakens the musculoskeletal system. A pathological fracture over the affected joint may occur under substantial stress, which eventually leads to collapse, re-fracture, and joint destruction (24). Surgical reconstruction of Charcot hindfoot and ankle is preferred in the modern era as the affected limb is often not brace-able due to limb malalignment and bony prominences secondary to the deformity (25). Charcot neuroarthropathy reconstruction aims to produce a stable, shoe-able, painless, and plantigrade foot $(7,8)$. Patient walking ability was noted to improve significantly post reconstruction (26). Reconstruction frequently fails due to loss of protective proprioception, poor bone quality, and impaired wound healing due to multiple comorbidities associated with Charcot neuroarthropathy. Therefore, a concept of "superconstruct" is warranted in these cases, where fusion is extended beyond the zone of injury; extremity shortening by bone resection is required for adequate reduction without undue tension on soft tissue enveloped via using the strongest device applied in maximal mechanical position (27). Arthrodesis is the most common procedure found among studies for Charcot reconstruction. It is beneficial to patients with instability, pain or recurrent ulceration that fails conservative management (28-33). In this review, eight out of 16 studies performed tibiotalocalcaneal arthrodesis to reconstruct Charcot neuroarthropathy of the ankle with 346 cases (63\%) recorded $(10,11,14,15,19,20,23,24)$. Tibiotalocalcaneal arthrodesis is a more common fusion site upon the reconstruction of Charcot neuroarthropathy than Tibiocalcaneal fusion with 197 cases recorded. Other than arthrodesis, we also found bone grafting, talectomy, and posterior tendo-Achilles lengthening commonly performed. A meticulous joint surface preparation aids in successful arthrodesis. Therefore, bone resection (talectomy) was done to realign the ankle and the hindfoot to create a plantigrade foot without tension upon reduction. Bone graft was needed to maintain reconstruction and aids in ossification and consolidation of corrected region postreconstruction. Soft tissue release (tendo-Achilles lengthening) reduces tension upon reconstruction and peak plantar pressure, preventing ulceration post-reconstruction and improving overall walking ability (34). Among internal fixations of ankle and hindfoot Charcot neuropathy reconstruction, retrograde intramedullary nail as used in 14 studies with one by Pawar coated the nail with antibiotic; a posterior blade plate was used by Murat for reconstruction. The intramedullary nail is a load-sharing device that allows early ambulation. It provides higher stability for axial compression and torsion than external fixation-illizarov or a circular frame according to a biomechanical study on the comminuted tibia shaft fracture model by Hasenboehler (35); it provides higher stability for axial compression and torsion. Due to the unsatisfactory bone quality of Charcot neuropathy, rigid fixation is mandatory to achieve union post-reconstruction. Intramedullary nail aids in evenly distributing compression force across the fusion side (36). L. Massari also proved that retrograde intramedullary nailing was effective and stiffer internally for tibiotalocalcaneal arthrodesis (37). Of 303 cases of retrograde nails among our data, the union rate was recorded as $83.1 \%(280 / 337)$, whereas $75 \%$ of the plates were used-a study by Murat et el. where a posterior angle blade plate was used in cases with previous intervention. The rationale of utilizing a blade plate via a posterior approach was to avoid wound complication with an adequate soft-tissue envelop for bone implant-graft coverage (9). 
TABLE 1 | A summary of data extraction for a systematic review based on patient demographics.

\begin{tabular}{|c|c|c|c|c|c|c|c|}
\hline \multirow[t]{2}{*}{ Investigator } & \multirow[t]{2}{*}{ Country } & \multirow{2}{*}{$\begin{array}{l}\text { Evidence } \\
\text { grading } \\
\text { (level) }\end{array}$} & \multirow{2}{*}{$\begin{array}{l}\text { Study design and } \\
\text { time frame for data } \\
\text { collection }\end{array}$} & \multirow{2}{*}{$\begin{array}{l}\text { Sample size and } \\
\text { CN classification }\end{array}$} & \multicolumn{2}{|c|}{ Participants characteristics } & \multirow{2}{*}{$\begin{array}{l}\text { Post- } \\
\text { operative } \\
\text { follow-up } \\
\text { (months) }\end{array}$} \\
\hline & & & & & Sex & Age (years) & \\
\hline Cinar et al. (9) & Turkey & IV & $\begin{array}{l}\text { Retrospective case } \\
\text { series, 2006-2008 }\end{array}$ & 4 patients & $\begin{array}{l}2 \text { males, } \\
2 \text { females }\end{array}$ & $\begin{array}{l}\text { 53-70 } \\
\text { (Mean 63) }\end{array}$ & $\begin{array}{l}12-35 \\
\text { (average }=24)\end{array}$ \\
\hline Chraim et al. (10) & Austria & IV & $\begin{array}{l}\text { Retrospective case } \\
\text { series Jan 2011-June } \\
2013\end{array}$ & $\begin{array}{l}18 \text { patients } \\
\text { (19 feet) } \\
\text { Sander pattern IV } \\
\text { (18) } \\
\text { Eichenholtz } \\
\text { stage III (18) }\end{array}$ & $\begin{array}{l}10 \text { males } \\
8 \text { females }\end{array}$ & $\begin{array}{l}\text { 38.5-79.8 } \\
\text { (Mean 63.43) }\end{array}$ & $\begin{array}{l}37-70 \\
(\text { mean }=46.36)\end{array}$ \\
\hline ElAlfy et al. (12) & Egypt & IV & $\begin{array}{l}\text { Prospective case } \\
\text { series, Feb 2010-Oct } \\
2013\end{array}$ & 27 patients & $\begin{array}{l}16 \text { males, } \\
11 \text { females }\end{array}$ & $\begin{array}{l}\text { 32-75 (Mean } \\
54)\end{array}$ & $\begin{array}{l}26-45 \\
(m e a n=31)\end{array}$ \\
\hline El-Mowafi et al. (13) & Egypt & IV & $\begin{array}{l}\text { Retrospective case } \\
\text { series, Jan } \\
\text { 2010-Dec2015 }\end{array}$ & $\begin{array}{l}24 \text { patients, } \\
\text { Brodsky Illa }\end{array}$ & $\begin{array}{l}7 \text { males, } \\
17 \text { females }\end{array}$ & $\begin{array}{l}\text { 43-62 (mean } \\
50.7 \text { ) }\end{array}$ & $\begin{array}{l}24-98(36.4 \\
\pm 5.8)\end{array}$ \\
\hline Emara et al. (14) & Egypt & IV & $\begin{array}{l}\text { Retrospective case } \\
\text { series, 2011-2016 }\end{array}$ & 42 patients & $\begin{array}{l}31 \text { males, } \\
11 \text { females }\end{array}$ & $\begin{array}{l}\text { 38-59 (Mean } \\
49.6 \text { ) }\end{array}$ & 12 \\
\hline Ettinger et al. (15) & Germany & IV & $\begin{array}{l}\text { Retrospective } \\
\text { case series Jun } \\
\text { 2010-March } 2015\end{array}$ & 58 patients & $\begin{array}{l}33 \text { males } \\
25 \text { females }\end{array}$ & $\begin{array}{l}26-81 \text { (mean } \\
59.1 \text { ) }\end{array}$ & $\begin{array}{l}12-57 \text { (mean } \\
=31.3)\end{array}$ \\
\hline $\begin{array}{l}\text { Siebachmeyer } \\
\text { et al. (18) }\end{array}$ & UK & IV & $\begin{array}{l}\text { Retrospective } \\
\text { case series Jan } \\
\text { 2008-April } 2013\end{array}$ & $\begin{array}{l}20 \text { patients ( } 21 \\
\text { feet) }\end{array}$ & $\begin{array}{l}12 \text { males, } \\
8 \text { females }\end{array}$ & $\begin{array}{l}46-83 \text { (means } \\
62.6)\end{array}$ & $\begin{array}{l}\text { 8-54 }(\text { mean }= \\
26)\end{array}$ \\
\hline Sundarajan et al. (23) & India & III & $\begin{array}{l}\text { Prospective study July } \\
2007 \text {-Dec } 2012\end{array}$ & $\begin{array}{l}33 \text { patients, } \\
\text { Eichenholtz, stage } \\
\text { I (9), stage II (13), } \\
\text { stage III (11) }\end{array}$ & $\begin{array}{l}19 \text { males, } \\
14 \text { females }\end{array}$ & $\begin{array}{l}41-76 \\
\text { (means 58) }\end{array}$ & 44 \\
\hline Vasukutty et al. (24) & UK & III & $\begin{array}{l}\text { Prospective case } \\
\text { series, Jun 2008-Sept } \\
2015\end{array}$ & $\begin{array}{l}40 \text { patients ( } 42 \\
\text { feet) }\end{array}$ & $\begin{array}{l}20 \text { males, } \\
20 \text { females }\end{array}$ & $\begin{array}{l}\text { 33-82 } \\
\text { (means 59) }\end{array}$ & 12 \\
\hline Kuharajan et al. (19) & Malaysia & IV & $\begin{array}{l}\text { Retrospective case } \\
\text { series, Jan 2011-Jun } \\
2016\end{array}$ & $\begin{array}{l}16 \text { patients, } \\
\text { Eichenholtz, stage } \\
\text { I (0), stage II (0), } \\
\text { stage III (16) }\end{array}$ & $\begin{array}{l}4 \text { males, } \\
12 \text { females }\end{array}$ & $\begin{array}{l}\text { 20-71 } \\
\text { (means 58.1) }\end{array}$ & At least 6 \\
\hline Pawar et al. (20) & USA & IV & $\begin{array}{l}\text { Therapeutic study } \\
(2008-2010)\end{array}$ & $\begin{array}{l}\text { Eichenholtz stage I } \\
\text { (1), stage II (0), } \\
\text { stage III (3) }\end{array}$ & $\begin{array}{l}4 \text { males, } 1 \\
\text { female }\end{array}$ & $46-82$ & $\begin{array}{l}12-24 \\
\text { (average }=18)\end{array}$ \\
\hline
\end{tabular}


TABLE 2 | A summary of data extraction for a systematic review based on a patient outcome.

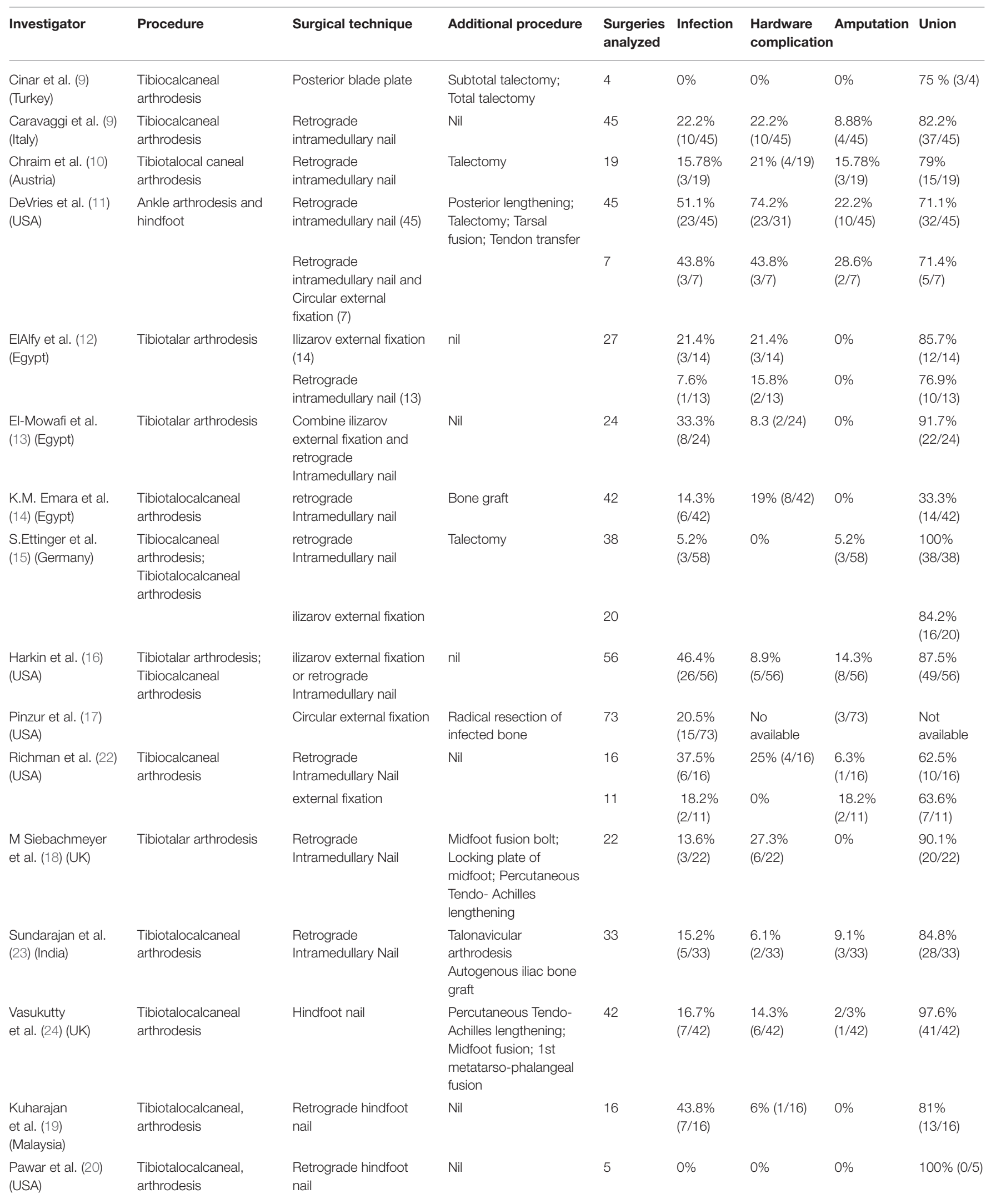


A circular external fixator offers a better bone and soft tissue tolerance without compromising blood supply as thin wires were used upon reconstruction. The construct of a circular external fixator allows axial micromotion of bone fragments during weight-bearing. Bony stabilization can be done by manipulating frame components without soft tissue tensioning $(29,38,39)$. There were a total of 157 circular external fixations recorded as the reconstruction of Charcot neuroarthropathy ankle among our searches. Thirty-five cases of the union were recorded among studies that applied external fixation, but two studies do not mention a union rate as the outcome $(16,17)$. Harkin did not specify the union rate according to the type of the fixation method of their cases, whereas Pinzur does not record bony union post-reconstruction of their patients. Therefore, the union rate of circular external fixation among available studies in Charcot reconstruction was $78 \%(35 / 45)$.

Hybrid construct that is utilized by El-Mowafi to combine intramedullary nail and circular external fixation shows a $100 \%$ limb salvage and $91.6 \%$ union (13). In the hybrid construct by El-Mowafi, the retrograde nail was unlocked distally. In the hybrid construct by El-Mowafi, the retrograde nail was unlocked distally.JG DeVries applied a similar construct in population with more comorbidities and complex deformity; however, there is $71.4 \%$ limb salvage, and a union rate was recorded among these cases (11). El-Mowafi proposed a continuous guided compression provided by circular external fixation across the reconstruction site when the intramedullary nail was unlocked distally, which is a more superior option compared to a fixed intramedullary nail. Both authors believe that circular external fixation provides additional stability upon reconstruction and protection during unintentional weight-bearing post-operation. Additional surgery-frame removal was warranted, which may be the disadvantage of this reconstruction form. Most of the studies that discuss Charcot ankle reconstruction focus on one hardware hindfoot arthrodesis. Hence, in our review, we investigated three studies that compare two or more hardware outcomes. El Alfy et al. compared external fixation with intramedullary nailing (12), as opposed to Richman et al.; the incidence of the complications was higher among the external fixator group than in the intramedullary nailing group (22). The risk of infection and the need for additional surgery were increased upon reconstruction as noted among cases that utilize external fixator to augment an intramedullary nail, compared to intramedullary nail alone by JG DeVries. Common hardware complications revealed among retrograde nails of our records were screw loosening (7.3\%) and migration (3.6\%). Screw loosening may cause implant or screw fracture, inadequate compression force distribution, and possible osseointegration failure. According to mechanical engineering, cyclic transverse loads were the culprit for the rotational loosening of screws $(40,41)$. According to Turner, the holding power of the screws was reduced in bones with lower mineral content, such as osteoporotic, by comparing healthy bovine bones and osteoporotic bones (42). As the bone quality of Charcot neuropathy is poor, the screws for reconstruction holding power were low. In a clinical study on hydroxyapatite (HA)-coated screw, the feature of surface roughness and the relative "oversising" of screw design prove to increase the torque of insertion and the purchase of a screw into the bone, which reduces the rate of screw loosening $(42,43)$. Siebachhmeyer and Vasukutty utilized HA-coated screws after observing screw loosening in a few of their initial cases that used the standard distal locking screw; there were no remaining cases that used HA-coated locking screws that were loosened and migrated $(18,24)$. However, there were no implant failures noted among cases that applied for a posterior blade plate despite a $50 \%$ rate of postoperative infection recorded (9). There were 8 cases of hardware complication recorded among studies reconstructed via circular external fixation $(11-13,16)$. However, no hardware complications were noted in 2 studies from Ettinger and Richman, who applied circular external fixators as tools for Charcot reconstruction $(15,22)$. Hardware complications were not recorded in the study by Pinzur (17). The amputation rate among collected data reconstructed via internal fixation was recorded as $7.17 \%(22 / 30)$ and $9.7 \%$ (16/164) among cases with circular external fixation. There was $100 \%$ limb salvage in Charcot reconstruction with hybrid fixation (combination of the intramedullary nail and circular external fixation) by El-Mowafi despite bony union that was achieved $91.7 \%$ in the series (13). About $71.4 \%$ of limb salvage was recorded in DeVries's study, where a retrograde nail was augmented with a circular external fixator (11). Ideal timing for Charcot ankle reconstruction is still a debatable topic among surgeons with various approaches and outcomes recorded. Traditionally, surgical reconstruction of Charcot neuroarthropathy was delayed till a later stage of the disease, but there is a risk of skin breakdown and introduction of the infection to bones and joints due to deformity progression. It was due to the belief that a higher rate of infection, wound healing issue, and implant failure when reconstruction was done during the acute phase of Charcot neuroarthropathy (7, 44-46). Most of the authors reconstruct the Charcot ankle at Stage II or III, according to Eichholtz. Early intervention in the early stage of the disease was suggested by Caravaggi (21) when pressure ulcer over bony prominences had not yet developed. B Elalfy also suggested intervention should be done when the deformity was endangered to the skin with a potential of ulcer occurrence (12). Most of the authors reconstructed the Charcot ankle during the chronic stage of the disease. However, there is no complication recorded post-reconstruction in Stage I Charcot in the Sundararajan study. Time for union is also shorter in those groups of patients than those reconstructing Stages II and III. According to the authors, there is no significant difference across the stages in terms of outcomes and complications (23). This study revealed two different surgical approaches upon reconstruction in the presence of osteomyelitis in Charcot neuroarthropathic ankle by utilizing an antibiotic-coated nail by Pawar (21) and a single stage of resection of infection, deformity correction via circular external fixation by Pinzur (17). Common treatment strategy in infected Charcot has been infection control via debridement, followed by procedures to achieve osseous union either by external or internal fixation. Pinzur recorded $95.7 \%$ limb salvage in the studies, but the circular external fixator was required to be removed after at least 12 weeks, where implant removal was not needed in Pawar study where amputation was not recorded. The antibiotic-coated nail provides local antibiotics 
and can serve as a stable definitive fixator in the infected Charcot neuroarthropathic limb. The limitation of the current study is failure to identify any Levels I and II studies to take note on surgical management on Charcot neuroarthropathy; it is probably due to uniqueness of the disease in each case, making surgical approach divert and a relatively small population of patients treated in this condition to allow a higher level of study to be conducted. Although it is difficult to conduct a prospective randomized-controlled study, such studies would contribute crucial appraisal on various fixation methods in the surgical reconstruction of the Charcot neuroarthropathy ankle. Multicentre studies and registries development can be helpful to achieve adequate patient numbers and increase the strength of the study.

\section{CONCLUSION}

In conclusion, evidence would suggest a retrograde intramedullary nail as the choice of reconstruction of the Charcot neuroarthropathy ankle before ulcer occurrence.

\section{REFERENCES}

1. Alam U, Riley DR, Jugdey RS, Azmi S, Rajbhandari S, D'Août K, et al. Diabetic neuropathy and gait: a review. Diabetes Ther. (2017) 8:125364. doi: 10.1007/s13300-017-0295-y

2. Leardini A, O'Connor JJ, Giannini S. Biomechanics of the natural, arthritic, and replaced human ankle joint. J Foot Ankle Res. (2014) 7:8. doi: 10.1186/1757-1146-7-8

3. Rogers LC, Frykberg RG, Armstrong DG, Boulton AJ, Edmonds M, Van GH, et al. The charcot foot in diabetes. Diabetes Care. (2011) 34:2123-9. doi: $10.2337 / \mathrm{dc} 11-0844$

4. Sanders, LJ, Frykberg, RG. The Charcot Foot (Pied de Charcot). In: Levin, ME, Bower, JH, Pfeifer, MA, editors. Levin's and O'Neal's The Diabetic Foot. 7th ed. Philadelphia, PA: Mosby Elsevier (2007). p. 257-83.

5. Brodsky JW. The diabetic foot. In: Coughlin MJ, Mann RA, Saltzman CL, editors. Surgery of the Foot and Ankle. 8. St Louis, MO, USA: Mosby. (2006). p. 1281-368.

6. Eichenholtz SN. Charcot Joints. Springfield, IL, USA: Charles C.Thomas; 1966

7. Lowery NJ, Woods JB, Armstrong DG, Wukich DK. Surgical management of Charcot neuroarthropathy of the foot and ankle: a systematic review. Foot Ankle Int. (2012) 33:113-21. doi: 10.3113/FAI.2012.0113

8. Wukich DK, Sung W. Charcot arthropathy of the foot and ankle: modern concepts and management review. J Diabetes Complications. (2009) 23:40926. doi: 10.1016/j.jdiacomp.2008.09.004

9. Cinar M, Derincek A, Akpinar S. Tibiocalcaneal arthrodesis with posterior blade plate in diabetic neuroarthropthy. Foot Ankle Int. (2010) 31:5116. doi: 10.3113/FAI.2010.0511

10. Chraim M, Krenn S, Alrabai HM, Trnka HJ, Bock P. Mid-term followup of patients with hindfoot arthrodesis with retrograde compression intramedullary nail in Charcot neuroarthropathy of the hindfoot. Bone Joint J. (2018) 100-B:190-6. doi: 10.1302/0301-620X.100B2.BJJ-20170374.R2

11. DeVries JG, Berlet GC, Hyer CF. A retrospective comparative analysis of Charcot ankle stabilization using an intramedullary rod with or without application of circular external fixator-utilization of the Retrograde Arthrodesis Intramedullary Nail database. J Foot Ankle Surg. (2012) 51:420-5. doi: 10.1053/j.jfas.2012.03.005

12. ElAlfy B, Ali AM, Fawzy SI. Ilizarov external fixator versus retrograde intramedullary nailing for ankle joint arthrodesis in diabetic charcot neuroarthropathy. J Foot Ankle Surg. (2017) 56:309-13. doi: 10.1053/j.jfas.2016.10.014
Due to poor bony quality in the Charcot neuropathy ankle, hydroxyapatite (HA)-coated screws are recommended for the locking mechanism to prevent migration. Hybrid fixation is recommended for reconstruction in the condition of ulceration and more complex deformity as it provides a higher rate of limb salvage with less soft tissue irritation.

\section{DATA AVAILABILITY STATEMENT}

The original contributions presented in the study are included in the article/supplementary material, further inquiries can be directed to the corresponding author.

\section{AUTHOR CONTRIBUTIONS}

MB, SD, IM, and SO: study design, revision and editing of the manuscript, statistical analysis and interpretation of results, and drafting of study protocol. MB and SO: drafting of the initial manuscript. All authors have read and approved the final manuscript.

13. El-Mowafi H, Abulsaad M, Kandil Y, El-Hawary A, Ali S. Hybrid fixation for ankle fusion in diabetic charcot arthropathy. Foot Ankle Int. (2018) 39:93-8. doi: 10.1177/1071100717735074

14. Emara KM, Ahmed Diab R, Amr Hemida M. Tibio-calcaneal fusion by retrograde intramedullary nailing in charcot neuroarthropathy. Foot (Edinb). (2018) 34:6-10. doi: 10.1016/j.foot.2017.11.003

15. Ettinger S, Plaass C, Claassen L, Stukenborg-Colsman C, Yao D, Daniilidis K. Surgical management of charcot deformity for the foot and ankle-radiologic outcome after internal/external fixation. J Foot Ankle Surg. (2016) 55:5228. doi: 10.1053/j.jfas.2015.12.008

16. Harkin EA, Schneider AM, Murphy M, Schiff AP, Pinzur MS. Deformity and clinical outcomes following operative correction of charcot ankle. Foot Ankle Int. (2019) 40:145-51. doi: 10.1177/1071100718 805076

17. Pinzur MS, Gil J, Belmares J. Treatment of osteomyelitis in charcot foot with single-stage resection of infection, correction of deformity, and maintenance with ring fixation. Foot Ankle Int. (2012) 33:106974. doi: 10.3113/FAI.2012.1069

18. Siebachmeyer M, Boddu K, Bilal A, Hester TW, Hardwick T, Fox TP, et al. Outcome of one-stage correction of deformities of the ankle and hindfoot and fusion in Charcot neuroarthropathy using a retrograde intramedullary hindfoot arthrodesis nail. Bone Joint J. (2015) 97-B:7682. doi: 10.1302/0301-620X.97B1.34542

19. Kuharajan R, Yazid BM, Ohnmar H, Yuliawiratman BS. Functional outcome of hindfoot arthrodesis in Charcot arthropathy. Med Health. (2019) 14:17282. doi: 10.17576/MH.2019.1401.14

20. Pawar A, Dikmen G, Fragomen A, Rozbruch SR. Antibiotic-coated nail for fusion of infected charcot ankles. Foot Ankle Int. (2013) 34:804. doi: 10.1177/1071100712460209

21. Caravaggi CM, Sganzaroli AB, Galenda P, Balaudo M, Gherardi P, Simonetti $\mathrm{D}$, et al. Long-term follow-up of tibiocalcaneal arthrodesis in diabetic patients with early chronic Charcot osteoarthropathy. J Foot Ankle Surg. (2012) 51:408-11. doi: 10.1053/j.jfas.2012.04.007

22. Richman J, Cota A, Weinfeld S. Intramedullary nailing and external ring fixation for tibiotalocalcaneal arthrodesis in charcot arthropathy. Foot Ankle Int. (2017) 38:149-52. doi: 10.1177/10711007166 71884

23. Sundararajan SR, Srikanth KP, Nagaraja HS, Rajasekaran S. Effectiveness of hindfoot arthrodesis by stable internal fixation in various eichenholtz stages of neuropathic ankle arthropathy. J Foot Ankle Surg. (2017) 56:2826. doi: 10.1053/j.jfas.2016.11.002 
24. Vasukutty N, Jawalkar H, Anugraha A, Chekuri R, Ahluwalia R, Kavarthapu V. Correction of ankle and hind foot deformity in Charcot neuroarthropathy using a retrograde hind foot nail-The Kings' Experience. Foot Ankle Surg. (2018) 24:406-10. doi: 10.1016/j.fas.2017.04.014

25. Van der Ven A, Chapman CB, Bowker JH. Charcot neuroarthropathy of the foot and ankle. J Am Acad Orthop Surg. (2009) 17:56271. doi: 10.5435/00124635-200909000-00003

26. Illgner U, Budny T. Frohne I, Osada N, Siewe J, Wetz HH. Clinical benefit and improvement of activity level after reconstruction surgery of Charcot feet using external fixation: 24-months results of 292 feet. BMC Musculoskelet Disord. (2014) 15:392-8. doi: 10.1186/1471-2474-15-392

27. Sammarco VJ, Chevillet J. The role of internal fixation in surgery of the Charcot foot and the evolution of "super- construct" techniques. Curr Orthop Pract. (2010) 21:233-9. doi: 10.1097/BCO.0b013e3181d7b172

28. Papa J, Miyerson M, Girard P. Salvage with arthrodesis, intractable diabetic arthropathy of the foot and ankle. J Bone Joint Surg Am. (1993) 82:105666. doi: 10.2106/00004623-199307000-00012

29. Zarutsky E, Rush SM, Schuberth JM. The use of circuler wire external fixation in the treatment of salvage ankle arthrodesis. J Foot Ankle Surg. (2005) 44:22-31. doi: 10.1053/j.jfas.2004.11.004

30. Simon SR, Tejwani SG, Wilson DL, Santner TJ, Denniston NL. Arthrodesis as an early alternative to nonoperative management of charcot arthropathy of the diabetic foot. J Bone Joint Surg Am. (2000) 82:935-50. doi: 10.2106/00004623-200007000-00005

31. Stone NC, Daniels TR. Midfoot and hindfoot arthrodeses in diabetic Charcot arthropathy. Can J Surg. (2000) 43:449-55. Available online at: https://www. canjsurg.ca/content/43/6/449

32. Fabrin J, Larsen K, Holstein PE. Long term follow-up in diabetic Charcot feet with spontaneous onset. Diabetes Care. (2000) 23:796800. doi: $10.2337 /$ diacare.23.6.796

33. Sticha RS, Frascone ST, Wertheimer SJ. Major arthrodeses in patients with neuropathic arthropathy. J Foot Ankle Surg. (1996) 35:560-6. doi: 10.1016/S1067-2516(96)80130-X

34. Lavery LA, Armstrong DG, Wunderlich RP, Tredwell J, Boulton AJ. Diabetic foot syndrome: evaluating the prevalence and incidence of foot pathology in Mexican Americans and non-Hispanic whites from a diabetes disease management cohort. Diabetes Care. (2003) 26:14358. doi: $10.2337 /$ diacare.26.5.1435

35. Hasenboehler E, Smith WR. Laudicina L, et al. Fatigue behavior of Ilizarov frame versus tibial interlocking nail in a comminuted tibial fracture model: a biomechanical study. J Orthop Surg Res. (2006) 1:16. doi: 10.1186/1749-799X-1-16

36. Brodsky JW, Verschae G, Tenenbaum S. Surgical correction of severe deformity of the ankle and hindfoot by arthrodesis using a compressing retrograde intramedullarynail. Foot \& Ankle International. (2014) 35:3607. doi: $10.1177 / 1071100714523270$

37. Massari L, Gildone A, Zerbinati F. Tibiotalocalcaneal arthrodesis by retrograde intramedullary nailing as a 'salvage procedure': clinical, radiographic and baropodometric evaluation of three cases. Foot and Ankle Surgery. (2002) 8:3-12. doi: 10.1046/j.1460-9584.2002.00286.x

38. Cooper PS. Aplication of external fixators for management of Charcot deformities of the foot and ankle. Foot Ankle Clin. (2002) 7:20754. doi: 10.1016/S1083-7515(02)00019-0

39. Bronson DG, Samchukov ML, Birch JG, Browne RH, Ashman RB. Stability of external circular fixation: a multi-variable biomechanical analysis. Clinical Biomechanics. 13:441-8. doi: 10.1016/S0268-0033(98)00007-2

40. Sanclemente JA, Hess DP. Parametric study of threaded fastener loosening due to cyclic transverse loads. Engineering Failure Analysis. (2007) 14:23949. doi: 10.1016/j.engfailanal.2005.10.016

41. Moroni A, Faldini C, Pegreffi F, Giannini S. HA-coated screws decrease the incidence of fixation failure in osteoporotic trochanteric fractures. Clin Orthop Relat Res. (2004) 425:87-92. doi: 10.1097/01.blo.0000132405.30139.bb

42. Turner IG, Rice GN. Comparison of bone screw holding strength in healthy bovine and osteoporotic human cancellous bone. Clin Mater. (1992) 9:1057. doi: 10.1016/0267-6605(92)90054-W

43. Sandén B, Olerud C, Petrén-Mallmin M, Larsson S. Hydroxyapatite coating improves fixation of pedicle screws. A clinical study. J Bone Joint Surg Br. (2002) 84:387-91. doi: 10.1302/0301-620X.84B3.0840387

44. Ministry of Health Malaysia management of diabetic foot (second edition). Kuala Lumpur: MOH. (2018)

45. Saltzman CL, Hagy ML, Zimmerman B, Estin M, Cooper R. How effective is intensive nonoperative initial treatment of patients with diabetes and Charcot arthropathy of the feet? Clin Orthop Relat Res. (2005) 435:18590. doi: 10.1097/00003086-200506000-00026

46. Wukich DK, Raspovic KM, Hobizal KB, Sadoskas D. Surgical management of Charcot neuroarthropathy of the ankle and hindfoot in patients with diabetes. Diabetes Metab Res Rev. (2016) 32:292-6. doi: 10.1002/dmrr.2748

Conflict of Interest: The authors declare that the research was conducted in the absence of any commercial or financial relationships that could be construed as a potential conflict of interest.

Publisher's Note: All claims expressed in this article are solely those of the authors and do not necessarily represent those of their affiliated organizations, or those of the publisher, the editors and the reviewers. Any product that may be evaluated in this article, or claim that may be made by its manufacturer, is not guaranteed or endorsed by the publisher.

Copyright (C) 2022 Bajuri, Ong, Das and Mohamed. This is an open-access article distributed under the terms of the Creative Commons Attribution License (CC BY). The use, distribution or reproduction in other forums is permitted, provided the original author(s) and the copyright owner(s) are credited and that the original publication in this journal is cited, in accordance with accepted academic practice. No use, distribution or reproduction is permitted which does not comply with these terms. 